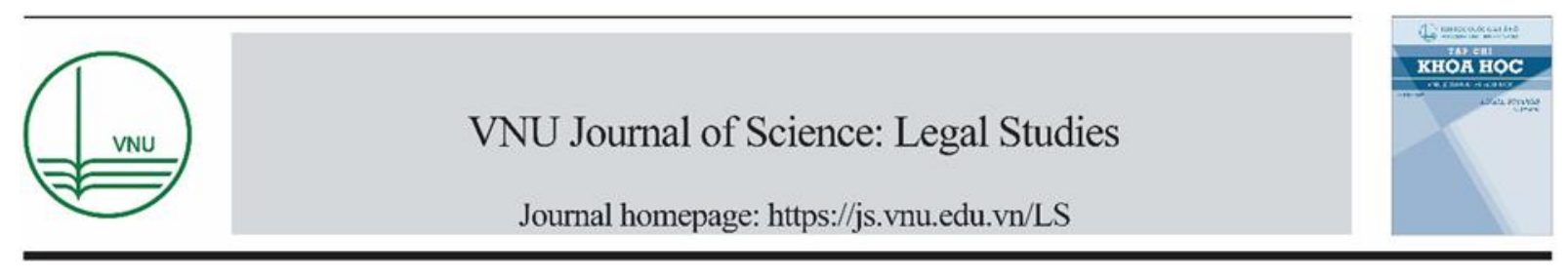

Review Article

\title{
Ensuring Justice for People with Intellectual Disabilities in Criminal Procedure
}

\author{
Vu Cong Giao ${ }^{1, *}$, Hoang Thi Bich Ngoc $^{2}$ \\ ${ }^{1}$ School of Law, Vietnam National University Hanoi, 144 Xuan Thuy, Cau Giay, Hanoi, Vietnam \\ ${ }^{2}$ Hanoi University of Procuracy, Duong Noi Ward, Ha Dong District, Hanoi, Vietnam
}

Received 17 April 2019

Revised 21 May 2019; Accepted 20 June 2019

\begin{abstract}
This paper analyzes the conditions for guaranteeing justice for people with intellectual disabilities. The paper argues that justice is a highly generalized category, reflecting the combined value system, relating to social morality, politics, law and the operation of the state apparatus. A person who wants access to justice must understand and wholly apply such factors as the legal system and law enforcement institutions. Yet, people with intellectual disabilities are those with special cognitive disabilities, making it difficult for them to understand and apply the stated factors. This requires that, people with intellectual disabilities, in addition to their own efforts, need support from the state, society and family to ensure their access to justice. Access to justice is a very important right of people with disabilities. Thus, ensuring access to justice in criminal proceedings is to ensure the rights, benefits, and dignity of this vulnerable group of people in society.
\end{abstract}

Keywords: Disable, intellectual disabilities, justice, criminal proceedings.

\footnotetext{
* Corresponding author.

E-mail address: giaovnu@gmail.com
}

https://doi.org/10.25073/2588-1167/vnuls.4193 


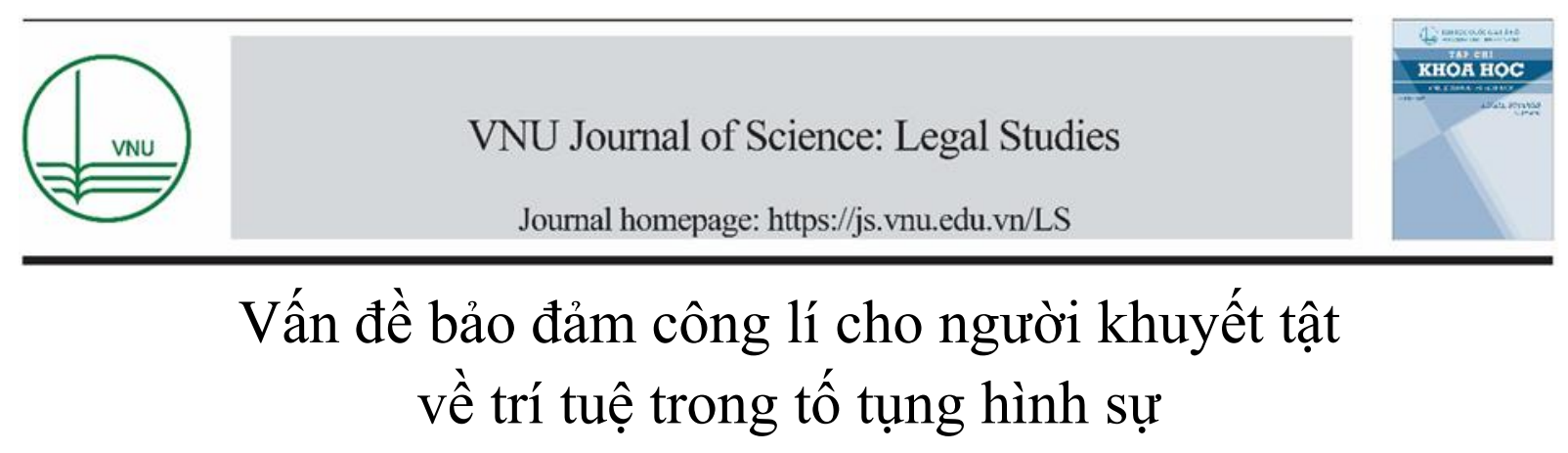

\author{
Vũ Công Giao ${ }^{1, *}$, Hoàng Thị Bích Ngọc ${ }^{2}$ \\ ${ }^{1}$ Khoa Luật, Đại học Quốc gia Hà Nội, 144 Xuân Thủy, Cầu Giấy, Hà Nội, Việt Nam \\ ${ }^{2}$ Truờng Đại học Kiểm sát Hà Nội, Phuờng Duoong Nội, Quận Hà Đông, Hà Nội, Việt Nam \\ Nhận ngày 17 tháng 04 năm 2019 \\ Chỉnh sửa ngày 21 tháng 5 năm 2019; Chấp nhận đăng ngày 20 tháng 6 năm 2019
}

\begin{abstract}
Tóm tắt: Bài viết phân tích những điều kiện bảo đảm công lí cho người khuyết tật về trí tuệ trong tố tụng hình sự. Theo các tác giả, công lí là một phạm trù có tính khái quát cao, phản ánh hệ giá trị tổng hợp, liên quan đến đạo đức xã hội, nền chính trị, pháp luật và hoạt động của bộ máy nhà nước. Một người muốn tiếp cận được công lí thì phải hiểu và vận dụng được tổng thể các yếu tố như: hệ thống pháp luật và các thiết chế thực thi pháp luật. Trong khi đó, người khuyết tật về trí tuệ là những cá nhân có những khiếm khuyết đặc biệt về mặt nhận thức, khiến cho họ khó có thể hiểu và vận dụng được những yếu tố đã nêu. Điều này đòi hỏi ngoài sự cố gắng của bản thân, họ cần phải có sự hỗ trợ của nhà nước, xã hội và gia đình mới bảo đảm được quyền tiếp cận công lí của mình. Tiếp cận công lí là quyền có ý nghĩa hết sức quan trọng với của người khuyết tật. Việc đảm bảo công lí trong tố tụng hình sự chính là bảo đảm các quyền, lợi ích, giá trị nhân phẩm của họ với tính cách là nhóm người dễ bị tổn thương trong xã hội.
\end{abstract}

Tù khóa: Khuyết tật, người khuyết tật trí tuệ, công lí, tố tụng hình sự.

\section{Khái niệm "công lí", "khuyết tật", "người khuyết tật thiểu năng trí tuệ"”}

\subsection{Khái niệm công lí}

“Công lî” (justice) là khái niệm đã được nhiều nhà tư tưởng trên thế giới đề cập và thảo luận trong suốt chiều dài lịch sử của nhân loại.

\footnotetext{
* Tác giả liên hệ.

Địa chi email: giaovnu@gmail.com

https://doi.org/10.25073/2588-1167/vnuls.4193
}

Khái niệm công lí được xác định dựa trên nhiều khía cạnh, góc độ tiếp cận, thể hiện những khác biệt giữa các nền văn hóa, giữa các thời điểm lịch sử khác nhau. Thời nay, quan điểm nổi bật về công lí là của nhà triết học chính trị hàng đầu của Mỹ J. Rawls. Ông coi 'công lí nhu là sư công bằng' (justice as fairness). Như vậy, để bảo đảm công bằng, tương tự như quyền con người, công lí phải được quy định bằng pháp luật và phải được bảo đảm thực hiện thông qua hệ thống tư pháp, mà cụ thể là tòa án.

Bảo đảm công lí là nền tảng cho một xã hội trật tự, an toàn, ổn định, văn minh, hạnh phúc 
và thịnh vượng. Từ góc độ chính trị học, công lí chính là một tiêu chí quan trọng để đánh giá tính ưu việt của một chế độ xã hội. Tính chính đáng, chính nghĩa của sự xuất hiện, tồn tại của một chính quyền thường được đánh giá thông qua việc chính quyền đó có thừa nhận, bảo vệ và bảo đảm công lí trong thực thi quyền lực nhà nước hay không. Từ góc độ khác, công lí là giá trị, phẩm hạnh giữ cho các thành viên trong xã hội gắn kết chặt chẽ với nhau vì lợi ích chung của toàn thể cộng đồng. Để đảm bảo sự ổn định và phát triển của cộng đồng, những đức hạnh như sự công bằng, liêm chính và tử tế cần phải được xem là nền tảng và phải được lan tỏa sâu rộng trong xã hội.

Về khía cạnh ngôn ngữ, khái niệm công lí cũng đã xuất hiện trong một số từ điển trong và ngoài nước. Ví dụ, ở nước ngoài, trong cuốn từ điển Luật Black (Black Law Dictionary), công lí được định nghĩa là "sụ công bằng và hơp lí, vớ ba ý niệm co bản: sư nhấn mạn về tầm quan trọng cá nhân, yêu cầu các cá nhân phải được đối xủ một cách phù hợ, không thiên vi và bình đẳng" [1]. Ở Việt Nam, trong một số cuốn Từ điển Tiếng Việt, công lí cũng đã được giải thích như là "Công lí là lẽ phải, lẽ công bằng, phù hợp với pháp luật đương thời, không thiên lệch, không tu vị. Chể độ nào cũng coi tòa án là tuợng trưng cho công lí, là cơ quan công lí của chế độ ấy" [2], "Công lí là sự nhận biềt đúng đắn và tôn trọng theo lẽ phải các quyền lợi ich chính đáng của moi ngườ" [3].

Ở Việt Nam, công lí và bảo vệ công lí được xác định là một trong những mục tiêu cơ bản của Chiến lược cải cách tư pháp đến năm 2020 (Nghị quyết số 49-NQ/TW ngày 02 tháng 06 năm 2005 của Bộ Chính trị). Cụ thể, Chiến lược này đã nêu rõ, cần: "Xây dựng nền tu pháp trong sạch, vũng manh, dân chủ, nghiêm minh, bảo vệ công lí, tùng buớc hiện đại, phuc vu nhân dân, phụng sư Tổ quốc Việt Nam xã họi chủ nghĩa; hoạt động tu pháp mà trong tâm là hoạt động xét xử được tiến hành có hiệu quả và hiệu lục cao". Cùng với đó, trong Văn kiện Đại hội đại biểu toàn quốc lần thứ XII của Đảng Cộng sản Việt Nam đã đề ra những biện pháp nhằm đảm bảo cơ sở chính trị cho hoạt động cải cách tư pháp, để từ đó xây dựng cơ quan tư pháp thật sự là chỗ dựa vững chắc trong hoạt động bảo vệ công lí và quyền con người. Cụ thể, về mục đích và lộ trình thực hiện, Văn kiện xác định: "Tiếp tuc đẩy mạnh việc thực hiện Chiến luợc cái cách tu pháp, xây dựng nền tu pháp trong sạch, vũng mạh, dân chủ, nghiêm minh, tùng bước hiện đại; bảo vệ pháp luật, công lí, quyền con nguời, quyền công dân, bảo vệ chế độ xã hội chủ nghĩa, lợi ich của Nhà nuoóc, quyền và lợi ich hợp pháp của co quan, tổ chức và cá nhân. Phân định rành mạch thẩm quyền quản lí hành chính vói trách nhiệm, quyền hạn tư pháp trong tổ chức, hoạt động của các co quan tu pháp" [4]. Như vậy, khái niệm công lí trong Chiến lược cải cách tư pháp và Văn kiện Đại hội XII của Đảng Cộng sản Việt Nam mang tính chất là một phạm trù gắn với lĩnh vực tư pháp, thể hiện qua việc xét xử bằng các thủ tục công bằng, hợp pháp, nhằm bảo vệ các quyền con người trong hoạt động tố tụng.

Nói tóm lại, mặc dù có những quan niệm khác nhau, nhưng xét tổng quát, công lí có thể được hiểu là việc bảo đảm sự công bằng, bình đẳng giữa con người với con người. Công lí gắn liền với việc bảo đảm danh dự, nhân phẩm, các quyền và lợi ích hợp pháp của mọi cá nhân, ngăn ngừa những hành xử tuỳ tiện, bạo ngược của các chủ thể trong xã hội, kể cả các cơ quan, viên chức nhà nước. Đây là một phạm trù đa diện, vừa mang tính pháp lí, vừa mang tính xã hội, đạo đức.

\subsection{Khái niệm "khuyết tật"}

Theo phân loại của Tổ chức Y tế thế giới (The World Health Organisation - WHO) có ba mức độ suy giảm khả năng là: khiếm khuyết (impairment), khuyết tật (disability) và tàn tật (handicap). Trong đó, khái niệm khiếm khuyết chỉ đến sự mất mát hoặc không bình thường của cấu trúc cơ thể liên quan đến tâm lí hoặc/và sinh lí; khái niệm khuyết tật chỉ đến sự giảm thiểu chức năng hoạt động, là hậu quả của sự khiếm khuyết; còn khái niệm tàn tật đề cập đến tình thế bất lợi hoặc thiệt thòi của người mang khiếm khuyết do tác động của môi trường xung quanh lên cuộc sống của họ [5]. 
Công ước về quyền của người khuyết tật do Đại hội đồng Liên hợp quốc thông qua vào năm 2007 nêu định nghĩa người khuyêt tật ở Điều 1 , là "những người có khiếm khuyết lâu dài về thể chất, tâm thần, trí tuệ, hay giác quan mà khi tương tác với nhiều rào cản khác nhau thì dẫn tới việc gây trở ngại cho sự tham gia đầy đủ và hiệu quả của họ trong xã hội trên cơ sở bình đẳng với những người khác”. Đây là định nghĩa mang tính pháp lí quốc tế đầu tiên về "người khuyết tật", vì vậy có ý nghĩa to lớn trong việc thống nhất những hành động và nỗ lực bảo vệ các quyền của người khuyết tật trên thế giới.

Ở cấp độ quốc gia, pháp luật của một số nước cũng đã nêu định nghĩa về "người khuyết tật" mà chia sẻ những thuộc tính cơ bản trong định nghĩa nêu trên. Cụ thể, theo Đạo luật chống phân biệt đối xử với người khuyết tật của Vương quốc Anh (Disability Discrimination Act, 2010), người khuyết tật được hiểu là cá nhân có một hoặc nhiều khiếm khuyết về thể chất hoặc tinh thần mà vì thế gây ra sự suy giảm đến khả năng thực hiện các hoạt động, sinh hoạt hằng ngày một cách đáng kể và kéo dài. Theo đạo luật này, xét về mặt thời gian tác động thì khiếm khuyết kéo dài hoặc sẽ có thể kéo dài phải từ 12 tháng trở lên (dưới 12 tháng thì thường không được xem là khuyết tật, trừ khi bị tái đi tái lại). Trong Đạo luật về người khuyết tật của Hoa Kỳ năm 1990 (Americans with Disablities Act of 1990) người khuyết tật được định nghĩa là cá nhân có sự suy yếu về thể chất hay tinh thần gây ảnh hưởng đáng kể đến một hay nhiều hoạt động quan trọng trong cuộc sống. Còn ở Việt Nam, Luật về người khuyết tật năm 2010 định nghĩa ở khoản 1 Điều 2, trong đó: "Người khuyết tật là người bị khiếm khuyết một hoặc nhiều bộ phận cơ thể hoặc bị suy giảm chức năng được biểu hiện dưới dạng tật khiến cho lao động, sinh hoạt, học tập gặp khó khăn".

Tóm lại, từ những phân tích trên, có thể thấy khuyểt tật là một hiện tượng phức tạp và có biểu hiện rất đa dạng. Khái niệm này phản ánh sự suy giảm về khả năng tương tác xã hội của một cá nhân mà xuất phát từ những vấn đề bất ổn nảy sinh trong chức năng của cơ thể của cá nhân đó. Về mặt hình thức, những biểu hiện và nhận thức về sự khuyết tật mang tính tương đồng ở các quốc gia, tuy nhiên việc đối xử với người khuyết tật có sự khác biệt nhất định giữa các xã hội, do nhiều nguyên nhân mà chủ yếu là về kinh tế, xã hội, văn hoá.

\subsection{Khái niệm người khuyết tật về trí tuệ}

Trong tiếng Anh, 'thiểu năng trí tuệ' (hay 'khuyết tật về trí tuệ') được thể hiện qua nhiều cụm từ có nội hàm tương tự nhau, ví dụ như 'intellectual disability', 'general learning disability' hoặc 'mental retardation'... Cụm từ general mental disability được sử dụng chủ yếu ở Vương quốc Anh [6], trong khi ở Hoa Kỳ và các văn kiện quốc tế hay trong các tài liệu học thuật của các học giả trên thế giới thường sử dụng cụm từ mental retardation. Tương ứng với cụm từ này là cụm từ mental retarded persons [7] ('người thiểu năng trí tuệ' hay 'người khuyết tật về trí tuệ').

Tình trạng thiểu năng trí tuệ được xác định trong Sách Trắng về Chăm sóc sức khỏe và xã hội với người thiểu năng trí tuệ ở Anh [8] qua ba tiêu chí như sau: (1) khả năng trí tuệ thấp (thường có chỉ số IQ thấp hơn 70 [9]); (2) suy giảm khả năng thích ứng xã hội; và (3) phát hiện thiểu năng trí tuệ từ lúc còn nhỏ. Như vậy, việc xác định một người có bị thiểu năng trí tuệ hay không phải xem xét sự hạn chế của người đó thông qua hai khía cạnh về năng lực, đó là khả năng nhận thức (khả năng học tập, đưa ra các quyết định và giải quyết các vấn đề,...) và khả năng thích ứng (những kĩ năng cần thiết trong cuộc sống hằng ngày như là giao tiếp, tương tác và quan tâm tới người khác).

Thiểu năng trí tuệ được phân chia thành hai dạng là hội chứng thiểu năng trí tuệ có biểu hiện rõ ràng (ví dụ, hội chứng Down, hội chứng Tớc-no); và hội chứng thiểu năng trí tuệ không biểu hiện rõ ràng (ví dụ, Alzheimer, trầm cảm, hay quên, hoang mang trong suy nghĩ). Theo báo cáo của Dự án Nghiên cứu Bệnh tật toàn cầu, ở thời điểm năm 2013, có khoảng 95 triệu 
người trên thế giới có hội chứng thiểu năng trí tuệ không biểu hiện rõ ràng [10].

Bên cạnh đó, Hiệp hội Tâm thần Hoa Kỳ cũng đã xác định thiểu năng trí tuệ là 'có sự bất thường trong chức năng trí tuệ nói chung, xuất hiện trong quá trình phát triển và có sự liên quan đến: một là, sự khiếm khuyết trong nhận thức, và hai là, khả năng thích ứng với xã hội, hoặc liên quan đến cả hai điều này' [11].

\section{Sự cần thiết, ý nghĩa của việc bảo đảm công lí cho người khuyết tật về trí tuệ trong tố tụng hình sự}

Theo một chuyên gia, bảo đảm công lí trong tố tụng hình sự chính là bảo đảm sự công bằng và các quyền, tự do của con người trong quá trình giải quyết vụ án hình sự [12]. Ở đây, các thủ tục tố tụng hình sự chính là những cơ chế, công cụ giúp mọi người tiếp cận công lí, song cũng có thể bị lợi dụng để vô hiệu hoá công lí. Để tố tụng hình sự là công cụ tiếp cận công lí của mọi người, cần phải đáp ứng các yêu cầu đó là: (i) Phải bảo đảm toà án có khả năng tìm kiếm sự thật và đưa ra những phán quyết chính xác; (ii) Phải bảo đảm thời gian xử lí vụ việc kịp thời, vì công lí bị trì hoãn là công lí bị từ chối (justice delayed is justice denied [13]); (iii) Chi phí tài chính cho việc tiếp cận với toà án phải hợp lí, không phải là rào cản đối với mọi người. Đây cũng được xem là những tiêu chí cơ bản dùng để đánh giá mức độ thành công trong cải cách tư pháp ở các quốc gia trên thế giới [14].

Một người khuyết tật về trí tuệ có thể tham gia vào quá trình tố tụng hình sự với tư cách là bị hại, bị cáo hoặc người làm chứng. Thực tế trên thế giới cho thấy nhiều người trong số họ không được đảm bảo đầy đủ các quyền tố tụng. Ví dụ, trong quá trình điều tra, xét hỏi, người khuyết tật về trí tuệ có thể dễ dàng bị "dẫn dắt" câu trả lời theo ý muốn của người thẩm vấn, bởi họ không đủ khả năng tương tác với câu hỏi và người hỏi. Hoặc trong quá trình cung cấp chứng cứ, người khuyết tật về trí tuệ thường không được hoặc không thể cung cấp chứng cứ trước tòa do những khiếm khuyết của họ. Chính vì vậy, nếu không có biện pháp bảo vệ đặc biệt, có thể dẫn đến oan sai trong các vụ án mà bị can, bị cáo là người khuyết tật về trí tuệ.

Công lí là một phạm trù có tính khái quát cao, phản ánh hệ giá trị tổng hợp, liên quan đến đạo đức xã hội, nền chính trị, pháp luật và hoạt động của bộ máy nhà nước. Vì vậy, một người muốn tiếp cận được công lí thì phải hiểu và vận dụng được tổng thể các yếu tố như: hệ thống pháp luật (hiểu biết về quyền, nội dung và thủ tục tố tụng hình sự); và các thiết chế thực thi pháp luật (tư pháp, hành chính, các thiết chế bổ trợ tư pháp...). Trong khi đó, người khuyết tật về trí tuệ là những cá nhân có những khiếm khuyết đặc biệt về mặt nhận thức, khiến cho họ khó có thể hiểu và vận dụng được những yếu tố đã nêu. Điều này đòi hỏi ngoài sự cố gắng của bản thân, họ cần phải có sự hỗ trợ của nhà nước, xã hội và gia đình mới bảo đảm được quyền tiếp cận công lí của người khuyết tật về trí tuệ. Sự hỗ trợ này không vi phạm nguyên tắc công bằng, mà là để bảo đảm sự công bằng thực chất khi mà nó giúp xóa bỏ những rào cản bất hợp lí với người khuyết tật về trí tuệ trong quá trình tố tụng [15].

Từ cách tiếp cận nêu trên, có thể thấy quyền tiếp cận công lí của người khuyết tật về trí tuệ bao hàm hai nội dung chính: (1) Họ có quyền được cung cấp hay hỗ trợ dịch vụ tư vấn, giải đáp về chính sách, pháp luật miễn phí; (2) Họ có được hỗ trợ và tạo điều kiện thuận lợi trong việc tham gia tố tụng, bao gồm việc khiếu nại, tố cáo để bảo vệ các quyền và lợi ích hợp pháp của mình. Quyền tiếp cận công lí của người khuyết tật nói chung và người khuyết tật về trí tuệ nói riêng là quyền có ý nghĩa hết sức quan trọng. Việc đảm bảo quyền này chính là bảo đảm các quyền, lợi ích, giá trị nhân phẩm của họ với 
tính cách là nhóm người dễ bị tổn thương trong xã hội, đặc biệt trong tố tụng hình sự.

\section{Bảo đảm công lí trong áp dụng tố tụng hình sự với người khuyết tật về trí tuệ: Các tiêu chuẩn và kinh nghiệm quốc tế}

Tuyên bố về quyền của người bị thiểu năng trí tuệ (Declaration on the Rights of Mentally Retarded Persons) của Liên Hợp quốc năm 1971 đã kêu gọi các quốc gia thực thi các biện pháp để đảm bảo Tuyên bố này trở thành cơ sở bảo vệ quyền của người bị khuyết tật về trí tuệ. Một trong số các nguyên tắc về quyền của người bị khuyết tật về trí tuệ mà Tuyên bố đã chỉ ra bao gồm: "Quyền được bảo vệ không bị bóc lột, lạm dụng và đối xử hạ nhục. Nếu bị truy tố vì bất kì tội gì thì họ có quyền được luật pháp xét xử công minh, có xem xét đầy đủ đến mức độ ảnh hưởng về tâm thần của họ." [16] và "Khi nào vì bệnh tật nghiêm trọng mà người khuyết tật về tâm thần không thể thực hiện được tất cả các quyền của họ một cách có ý nghĩa, hay cần thiết phải hạn chế hoặc phủ nhận một số trong những quyền đó thì thủ tục áp dụng để hạn chế hay phủ nhận phải có sự bảo vệ về mặt pháp lí thích hợp chống mọi hình thức lạm dụng. Thủ tục này phải dựa vào sự đánh giá của các chuyên gia có trình độ về khả năng xã hội của người khuyết tật về tâm thần và phải tùy thuộc vào sự xem xét định kỳ và quyền được kháng cáo lên những nhà chức trách có thẩm quyền cao hơn." [17]. Vấn đề then chốt của hai nguyên tắc này đó là người khuyết tật về trí tuệ có quyền được xét xủ công bằng (due process of law) và công nhận sư giới hạn về khả năng nhận thức của ho (recognition of their individual capacities and limitations).

Trong bài viết của tác giả Paul R. Friedman về quyền con người và quyền pháp lí của người khuyết tật về trí tuệ [18], ông đã đề cập đến quyền của người khuyết tật về trí tuệ trong hệ thống tư pháp hình sự Mỹ và chỉ ra vấn đề quan trọng nhất mà người bị thiểu năng trí tuệ phải đối diện trong tố tụng hình sự đó là khả năng nhận thức bị hạn chế và góc nhìn nhạy cảm dành cho người bị thiểu năng trí tuệ từ các chủ thể có thẩm quyền tiến hành tố tụng như cảnh sát, luật sư và thẩm phán. Nếu xác định sai yếu tố nhận thức trong một vụ án hình sự thì dễ dàng dẫn đến việc các vấn đề pháp lí mà bị hại đưa ra để chống lại bị cáo không được xem xét một cách công bằng. Do đó, việc xác định khả năng của người được cho là bị thiểu năng trí tuệ là yếu tố quan trọng, cần phải cân nhắc kĩ càng trong quá trình tố tụng để xác định trách nhiệm hình sự và xác định tính chính xác, tính khách quan trong lời thú tội.

Trong giai đoạn xét hỏi, theo pháp luật Mỹ, nếu người bị cáo buộc phạm tội bị ép nhận tội thì những lời thú tội đó không được dùng làm bằng chứng chống lại người bị cáo buộc phạm tội [19]. Điều này thứ nhất là để đảm bảo công bằng và thứ hai là để chống sự nhầm lẫn dẫn đến buộc tội người vô tội. Đó là bởi trong thực tế, một người bị thiểu năng trí tuệ, dù bị ép buộc nhận tội hay không thì thông thường họ cũng không có đủ năng lực nhận thức để hiểu được thủ tục tố tụng, những hậu quả từ lời thú tội và những quyền hiến định mà họ được hưởng (ví dụ như quyền im lặng, quyền có luật sư tư vấn,..).

Trong giai đoạn xét xử, thông thường, người bị tâm thần không có khả năng hầu tòa, song họ vẫn phải chịu trách nhiệm dân sự và họ sẽ phải hầu tòa sau khi nhận thức được phục hồi. Ngược lại, không giống như người bị tâm thần, người bị thiểu năng trí tuệ không có khả năng hầu tòa, cũng không có khả năng thực hiện các trách nhiệm dân sự cả hiện tại và trong tương lai vì ít có khả năng hồi phục nhận thức.

Xét về trách nhiệm hình sự, mặc dù tiêu chí để xác định khuyết tật về tâm thần là khác nhau trong các phán quyết khác nhau của tòa án, nhưng có một 'phép thử chung' đã được công nhận rộng rãi bởi Viện Pháp luật Mỹ (1962), đó là: "Một người sẽ không phải chịu trách nhiệm hình sự cho hành vi của mình nếu tại thời điểm người đó thực hiện hành vi phạm tội, vì lí do mắc bệnh tâm thần hoặc vì hạn chế năng lực nhận thức, người đó không thể nhận thức được hành vi của mình là trái với pháp luật". 
Về vấn đề này, Ủy ban Nhân quyền Úc (Australian Human Rights Commision) đã đưa ra một số biện pháp thiết thực để bảo đảm quyền tiếp cận công lí của những người khuyết tật thiểu năng trí tuệ nói riêng hay khuyết tật về tâm thần nói chung trong tố tụng hình sự. Các biện pháp được chỉ ra bao gồm:

- Trong quá trình xét hỏi, cán bộ điều tra phải cung cấp các thông tin cần thiết về diễn biến của hoạt động (ví dụ như băng ghi âm, ghi hình,...) và cần giúp đỡ người khuyết tật hiểu về điều mà họ đang được hỏi cũng như những quyền mà họ được áp dụng trong quá trình xét hỏi;

- Hệ thống trợ giúp pháp lí phải nhận thức được những khó khăn mà người bị thiểu năng trí tuệ đang phải đối mặt trong hệ thống tư pháp hình sự để có thể cung cấp sự hỗ trợ kịp thời;

- Thủ tục tố tụng ở tòa án và nguyên tắc chứng minh phải được áp dụng dựa trên việc đảm bảo nhu cầu thiết yếu của người khuyết tật;

- Tăng cường sự hỗ trợ và sự thấu hiểu của tòa án và thẩm phán đối với những khó khăn mà người khuyết tật đang phải gánh chịu, các cơ quan nhà nước cần nghiên cứu quy định một số hình phạt phù hợp hơn với nhóm người này.

- Đảm bảo quyền không bị đối xử ngược đãi bởi các cơ quan thi hành tố tụng, và nếu trong trường hợp có cáo buộc người khuyết tật bị đối xử ngược đãi thì cơ quan nhà nước phải có nghĩa vụ điều tra và giải quyết kịp thời.

Tương tự, tổ chức phi chính phủ JUSTICE [20] ở Vương Quốc Anh đã xuất bản một báo cáo về Sức khỏe tâm thần và Xét xử công bằng [21] (Report on Mental Health and Fair Trial) bởi Nhóm nghiên cứu do các chuyên gia pháp lí và $\mathrm{y}$ tế uy tín hàng đầu soạn thảo. Báo cáo được soạn thảo dựa trên sự đánh giá thực tế của nhóm nghiên cứu khi họ cho rằng, quá trình tố tụng kể từ thời điểm cảnh sát tiếp nhận vụ việc đến khi chính thức bị buộc tội bằng các phán xét của tòa án vẫn còn tồn tại những vấn đề khiến cho quyền được xét xử công bằng của những người khuyết tật về tâm thần hoặc thiểu năng trí tuệ chưa được đảm bảo. Từ lí do này, nhóm nghiên cứu đã đề xuất 52 giải pháp cụ thể trong lĩnh vực tố tụng hình sự nhằm đảm bảo quyền cho nhóm người có khuyết tật về tâm thần hoặc thiểu năng trí tuệ nói chung. Những giải pháp này đề cập đến những phương diện chủ yếu sau:

- Giai đoạn điều tra: trong giai đoạn này, những chuyên gia y học về tâm thần sẽ thay các cán bộ điều tra làm nhiệm vụ giám định sức khỏe tâm thần cho những người bị buộc tội; nếu sau khi được giám định và xác định người đó có bị khuyết tật tâm thần hoặc thiểu năng trí tuệ thì nhà nước phải hỗ trợ những người đó bằng các biện pháp hỗ trợ phù hợp;

- Giai đoạn truy tố: có một công tố viên được tập huấn chuyên biệt tham gia xét xử những vụ án có người bị buộc tội bị khuyết tật về tâm thần hoặc thiểu năng trí tuệ;

- Giai đoạn xét xử: cũng có một thẩm phán được đào tạo chuyên biệt cho những phiên tòa có bị cáo là người bị khuyết tật tâm thần hoặc thiểu năng trí tuệ trực tiếp điều hành và chỉ đạo triển khai;

- Bài kiểm tra năng lực pháp lí: Bài kiểm tra năng lực để tự biện hộ và khả năng tham dự phiên tòa phải là bước đầu tiên bắt buộc phải làm trước khi phiên tòa diễn ra. Lí do biện hộ 'do bị tâm thần/thiểu năng' nên được thay bằng 'không phải chịu trách nhiệm hình sự do có khuyết tật đã được chuyên gia y tế thẩm định';

- Kết án: cần phải có văn bản pháp luật hướng dẫn về việc kết án đối với nhóm người dễ bị tổn thương và người có vấn đề về tâm thần, quy định một số hình thức kết án cụ thể và đa dạng hơn để đáp ứng được nhu cầu giải quyết vụ án.

Những giải pháp nêu trên được tạo ra dựa trên nhu cầu thực tế và trở thành một nguồn tham khảo uy tín dành cho các nhà làm luật. Nếu những vấn đề còn tồn tại giữa tòa án và người tham gia tố tụng là nhóm người bị tâm thần hoặc thiểu năng trí tuệ không được giải quyết, việc xét xử công bằng đối với nhóm người này khó có thể được đảm bảo. Những đề xuất trong báo cáo này không những được tác động đến hệ thống pháp luật Anh mà còn có giá 
trị tham khảo cao đối với các quốc gia khác, trong đó có Việt Nam.

\section{Bảo đảm công lí trong áp dụng tố tụng hình sự với người khuyêt tật ở Việt Nam: Thực trạng và một số đề xuất thúc đẩy}

Ở Việt Nam, định nghĩa về khuyết tật trí tuẹ được quy định tại Khoản 5 Điều 2 Nghị định 28/2012/NĐ-CP, theo đó: 'Khuyết tật trí tuệ là tình trạng giảm hoặc mất khả năng nhận thức, tư duy biểu hiện bằng việc chậm hoặc không thể suy nghĩ, phân tích về sự vật, hiện tượng, giải quyết sự việc". Theo kết quả Điều tra quốc gia người khuyết tật Việt Nam năm 2016 [22] (được công bố vào tháng 1 năm 2019) thì cả nước có 6.225 .519 người khuyết tật, trong đó người khuyết tật về nhận thức có 2.622.578 người. Nhìn từ những con số đó, có thể thấy người bị khuyết tật về nhận thức chiếm tỷ lệ cao, lên đến hơn một phần ba tổng số người khuyết tật ở Việt Nam hiện nay.

Việc bảo vệ quyền con người nói chung và người khuyết tật nói riêng trong lĩnh vực tư pháp hình sự, bao gồm các giai đoạn điều tra, truy tố, xét xử, thi hành án và cả trong quá trình giam giữ, cải tạo phạm nhân, đều cần dựa trên nguyên tắc đảm bảo mọi hành vi phạm tội đều được phát hiện kịp thời và xử lí nghiêm minh, song cũng không được làm oan người vô tội và bỏ lọt người phạm tội. Người phạm tội phải được đưa ra xét xử và phải chịu hình phạt tương xứng đối với hành vi phạm tội mà họ đã gây ra. Tuy nhiên, mục đích của hình phạt không chỉ mang tính trừng trị mà còn mang tính giáo dục, cải tạo, răn đe và phòng ngừa tội phạm. Đây chính là yêu cầu cơ bản để bảo đảm quyền con người nói chung và người khuyết tật nói riêng trong nhà nước pháp quyền xã hội chủ nghĩa. Về vấn đề này, trong Điều 3 Hiến pháp năm 2013 đã ghi rõ: 'Nhà nước bảo đảm và phát huy quyền làm chủ của Nhân dân; công nhận, tôn trọng, bảo vệ và bảo đảm quyền con người, quyền công dân; thực hiện mục tiêu dân giàu, nước mạnh, dân chủ, công bằng, văn minh, mọi người có cuộc sống ấm no, tự do, hạnh phúc, có điều kiện phát triển toàn diện.'

Trong Bộ luật Tố tụng hình sự 2015, vấn đề bảo vệ quyền con người (bao gồm cả người khuyết tật) được quy định tại một số điều luật khác nhau như: Điều 4 'Tôn trọng và bảo vệ các quyền cơ bản của công dân'; Điều 6 'Bảo đảm quyền bất khả xâm phạm về thân thể công dân'; Điều 7 'Bảo hộ tính mạng, sức khỏe, danh dự, nhân phẩm, tài sản của công dân; Điều 8 'Bảo đảm quyền bất khả xâm phạm về chỗ ở, an toàn và bí mật thư tín, điện thoại, điện tín của công dân'; Điều 9 'Không ai bị coi là có tội khi chưa có bản án kết tội của Tòa án đã có hiệu lực pháp luật'; Điều 11 'Bảo đảm quyền bào chữa của người bị tạm giữ, bị can, bị cáo'. Ngoài các quy định chung này, Bộ luật Tố tụng Hình sự còn có một số quy định cụ thể liên quan trực tiếp đến việc bảo vệ người khuyết tật, cụ thể như quy định Điều 76 trong đó nêu rằng mọi trường hợp nếu bị can, bị cáo là người có nhược điểm về tâm thần hoặc thể chất thì các cơ quan tiến hành tố tụng phải có trách nhiệm yêu cầu đoàn luật sư phân công người bào chữa cho họ, nếu không có người bào chữa cho họ trong trường hợp này là vi phạm nghiêm trọng luật tố tụng hình sự. Bên cạnh đó, Điều 21 của Bộ luật Hình sự 2015 quy định: Người thực hiện hành vi nguy hiểm cho xã hội trong khi đang mắc bệnh tâm thần, mắc bệnh khác làm mất khả năng nhận thức hoạc khả năng điều khiển hành vi của mình thì không phải chịu trách nhiệm hình sự. Để xác định chính xác người thực hiện hành vi nguy hiểm cho xã hội có mắc bệnh tầm thần hay không, Bộ luật Tố tụng hình sự 2015 yêu cầu đây là một trong những trường hợp bắt buộc phải trưng cầu giám định (tại khoản 1 Điều 206). Nếu kết quả giám định cho thấy người thực hiện hành vi nguy hiểm cho xã hội trong khi mắc bệnh tâm thần hoặc mắc bệnh khác làm mất khả năng nhận thức hoặc điều khiển hành vì thì Viện Kiểm sát hoặc Tòa án căn cứ vào kết quả này đưa họ vào một cơ sở điều trị chuyên khoa để bắt buộc chữa bệnh mà không phải chịu trách nhiệm hình sự về hành vi mình đã thực hiện. 
Những quy định nêu trên thể hiện chính sách của Nhà nước trong việc bảo vệ quyền con người đối với người có nhược điểm về tâm thần hoặc thể chất khi họ tham gia tố tụng hình sự và không để họ bị bất lợi khi tham gia tố tụng hình sự. Những quy định này cũng có sự tương đồng với pháp luật của một số quốc gia trên thế giới như phân tích ở phần trước.

Tuy nhiên, có một số vấn đề được đặt ra trong thực tiễn hiện nay, trong đó bao gồm việc làm rõ câu hỏi 'thế nào là người có nhuợc điểm về tâm thần và thể chất?'. Bộ luật Tố tụng Hình sự năm 2015 không có quy định nào và cũng chưa có văn bản pháp luật nào hướng dẫn cụ thể về vấn đề này. Điều đó đã tạo ra những cách hiểu khác nhau trong giải thích và áp dụng pháp luật tố tụng với người có nhược điểm về tâm thần và thể chất mà tiềm ẩn khả năng dẫn đến oan sai hoặc để lọt tội phạm. Thêm vào đó, có thể thấy, hiện pháp luật Việt Nam chưa có bất kì quy định cụ thể nào về bảo vệ quyền của người khuyết tật trong tố tụng hình sự, trong khi đã có quy định về quyền của các nhóm dễ bị tổn thương khác như phụ nữ, trẻ em, người thuộc các dân tộc thiểu số...

Từ những phân tích trên, có thể đề xuất một số giải pháp nhằm nâng cao khả năng tiếp cận công lí cho người khuyết tật nói chung và người khuyết tật về trí tuệ nói riêng trong tố tụng hình sự ở Việt Nam hiện nay như sau:

Thứ nhất, cần có quy định cụ thể và văn bản hướng dẫn về việc xác định như thế nào là người có nhược điểm về tâm thần hoặc thể chất bằng cách phân chia các nhóm nhược điểm có tính tương đồng với nhau một cách rõ ràng. Việc này sẽ giúp cho các cơ quan và người thực thi pháp luật có thể áp dụng pháp luật thống nhất, tránh oan sai và đảm bảo thực thi công lí trong mọi trường hợp.

Thứ hai, cần có những quy định riêng, cụ thể hơn về bảo đảm quyền của người khuyết tật trong luật tố tụng hình sự, bởi người khuyết tật là một nhóm đặc biệt, cần được bảo đảm những điều kiện tố tụng phù hợp với tình trạng và đặc điểm về thể chất cũng như tinh thần của họ. Việc này sẽ giúp nâng cao hiệu quả bảo vệ quyền và lợi ích của người khuyết tật cũng như đảm bảo công lí xuyên suốt quá trình tố tụng.

Thứ ba, cần đào tạo hoặc đào tạo bổ sung để xây dựng một đội ngũ cán bộ thực thi pháp luật tố tụng có hiểu biểt đầy đủ về đặc thù và các quyền của người khuyết tật trong tố tụng hình sự. Thành phần cần được đào tạo hay đào tạo lại bao gồm cả cán bộ điều tra, công tố viên, thẩm phán, giám thị trại giam...Việc này là để phòng ngừa những vi phạm và tăng cường mức độ bảo đảm quyền của người khuyết tật trong mọi giai đoạn của tố tụng hình sự.

\section{Lời cảm ơn}

Bài viết được thực hiện trong khuôn khổ Đề tài: "Công lý và quyền tiếp cận công lý ở Việt Nam" (mã số 505.01-2017.01) do Quỹ Khoa học và Công nghệ quốc gia (NAFOSTED) tài trợ.

\section{Tài liệu tham khảo}

[1] Henry Campbell Black M.A. St.Paul, Minn, Tù điển Luật Black (Black's Law Dictionary), NXB West Publishing Co, 1983 (447).

[2] Viện ngôn ngữ học, Từ điển Tiếng Việt, NXB Từ điển Bách khoa, (1999) 210.

[3] Nguyễn Lân, Từ và ngữ Tiếng Việt, NXB Tổng hợp Hồ Chí Minh, 2006.

[4] Đảng cộng sản Việt Nam, Văn kiện Đại hội Đại biểu toàn quốc lần thứ XII, Văn phòng Trung ương Đảng, (2016) 114.

[5] http://www.who.int/topics/disabilities/en/.

[6] Mary Lowth, Nghiên cứu chung về khuyết tật nhận thức (General Learning Disability), The Information Standard (2016). https://patient.info/doctor/general-learning-disability.

[7] Harkin, Báo cáo số 111-244 về Luật ROSA (Report 111-244 on ROSA'S LAW), Washington D.C (2010)

https://www.gpo.gov/fdsys/pkg/CRPT111srpt244/pdf/CRPT-111srpt244.pdf.

[8] Sách Trắng về sức khỏe và chăm sóc xã hội cho người bị khuyết tật về trí tuệ năm 2001 (The 2001 
White Paper on the health and social care of people with learning disabilities).

[9] Chỉ số IQ có thang điểm trung bình là 100 , hầu hết mọi người có $\mathrm{IQ}$ từ 85 đến 115 . Một người được xác định có khả năng cao bị thiểu năng trí tuệ nếu chỉ số IQ của họ thấp hơn từ 70 đến 75 .

[10] Nghiên cứu về Gánh nặng bệnh tật toàn cầu năm 2013, Collaborators, (2015)

https://www.ncbi.nlm.nih.gov/pmc/articles/PMC4 $561509 /$.

[11] Hiệp Hội tâm thần Hoa, Cẩm nang chẩn đoán và thống kê về rối loạn tâm thần 14, (1968) 2d ed.,.

[12] Nguyễn Ngọc Chí, Công lí và quyền tiếp cận công lí: Những vấn đề lí luận, thực tiễn, NXB Hồng Đức, (2018) 176.

[13] William Penn, Những loài trái cây cô đơn (Some Fruits of Solitude), Headley Brothers Pub., (1905) 86.https://archive.org/stream/somefruitssolit00pen ngoog\#page/n9/mode/1up.

[14] Adrian Zuckerman, Khủng hoảng trong tư pháp, từ khủng hoảng tư pháp dân sự: các quan điểm so sánh (Justice in Crisis, from Civil Justice in Crisis: Comparative Perspectives of Civil Procedure), Oxford University Press, 1999.

[15] Trần Thái Dương (2018), Công lí và Quyền tiếp cận công lí: Những vấn đề lí luận và thực tiễn, NXB Hồng Đức, ( 2018) 372.
[16] Nguyên tắc 6, Tuyên bố về Quyền của người bị thiểu năng trí tuệ của Liên Hợp quốc.

[17] Nguyên tắc 7, Tuyên bố về Quyền của người bị thiểu năng trí tuệ của Liên Hợp quốc.

[18] Paul R. Friedman (1977), Quyền con người và quyền luật pháp của người bị thiểu năng trí tuệ (Human and Legal rights of mentally retarded persons), International Journal of Mental Health. (1977) 50-72.

DOI: 10.1080/00207411.1977.11448756.

[19] Tổ công tác của Văn phòng Tổng thống nghiên cứu về thiểu năng trí tuệ, 1963.

[20] Tổ chức Justice được thành lập năm 1957 bởi một nhóm các nhà luật gia hàng đầu để thúc đẩy pháp quyền và quản trị công bằng. Justice trở thành thành viên của Ủy ban luật gia quốc tế của Vương Quốc Anh với sự tham gia của tất cả thành viên của các Đảng.

[21] https://2bquk8cdew6192tsu41lay8twpengine.netdna-ssl.com/wpcontent/uploads/2017/11/JUSTICE-MentalHealth-and-Fair-Trial-Report-2.pdf.

[22] Tổng cục Thống kê, Điều tra quốc gia về người khuyết tật, (2016)

https://www.gso.gov.vn/default.aspx?tabid=460\&i dmid=5\&ItemID=19054. 